\title{
Optimizing the recovery from heavy oil fields in the Middle East
}

\author{
Kamal Bennaceur, Schlumberger.
}

Heavy oil reserves in the Middle East stand at 80 billion barrels, and resources estimated in the range of one trillion barrels. Production challenges in the area include the characterization and completion of carbonate reservoirs that are naturally fractured. Oman, Kuwait and the Neutral Zone have developed heavy oil fields, while Bahrain, Egypt and other countries are in an advanced assessment phase.

The presentation will discuss the new technology developments in reservoir characterization, drilling and production, and the expected recovery factors associated with the EOR processes in carbonate reservoirs. The impact of carbon pricing in energy/emissions-intensive recovery processes is presented, along with a cost-curve under different emission pricing schemes. 